\title{
Determination of thermodynamics and design parameters for ionic liquid-induced cloud point extraction of Coralene red dye
}

\author{
D. R. Bhatt ${ }^{1}$ - K. C. Maheria ${ }^{1} \cdot$ J. K. Parikh ${ }^{2}$
}

Received: 21 March 2014/Revised: 21 July 2015/Accepted: 5 August 2015/Published online: 4 September 2015

(C) Islamic Azad University (IAU) 2015

\begin{abstract}
In the last decade, increasing interest on the use of aqueous micellar solution has been found in the field of separation science. The unique physical and chemical properties of ionic liquids make them most suitable candidates as an additive with nonionic surfactants in cloud point extraction. A surfactant-mediated cloud point extraction process has been adopted for the removal of Coralene red dye using tetraethyl ammonium tetrafluoroborate ionic liquid as an additive with nonionic surfactant Triton X-100. The detailed study on effect of various operating parameters such as temperature, time, concentration of surfactant, dye and IL on extraction of dye has been carried out to find out optimum conditions. The extraction of dye was found to be increased with temperature, time, surfactant concentration and IL concentration. A developed Langmuir isotherm was used to compute the feed surfactant concentration required for the removal of Coralene red dye up to an extraction efficiency of $90 \%$. The effect of temperature and concentration of surfactant and dye on various thermodynamic parameters was examined, and it was found that the values of $\Delta G^{0}$ increased with temperature and decreased with surfactant
\end{abstract}

Electronic supplementary material The online version of this article (doi:10.1007/s13762-015-0877-z) contains supplementary material, which is available to authorized users.

J. K. Parikh

jk_parikh@yahoo.co.in

1 Applied Chemistry Department, Sardar Vallabhbhai National Institute of Technology, Ichchhanath, Surat, Gujarat 395007, India

2 Chemical Engineering Department, Sardar Vallabhbhai National Institute of Technology, Ichchhanath, Surat, Gujarat 395007, India and dye concentration. The values of $\Delta H^{0}$ and $\Delta S^{0}$ increased with surfactant concentration and decreased with dye concentration. The developed approach for IL-assisted cloud point extraction has proved to be an efficient and green route for extraction of Coralene red from water sample.

Graphical Abstract

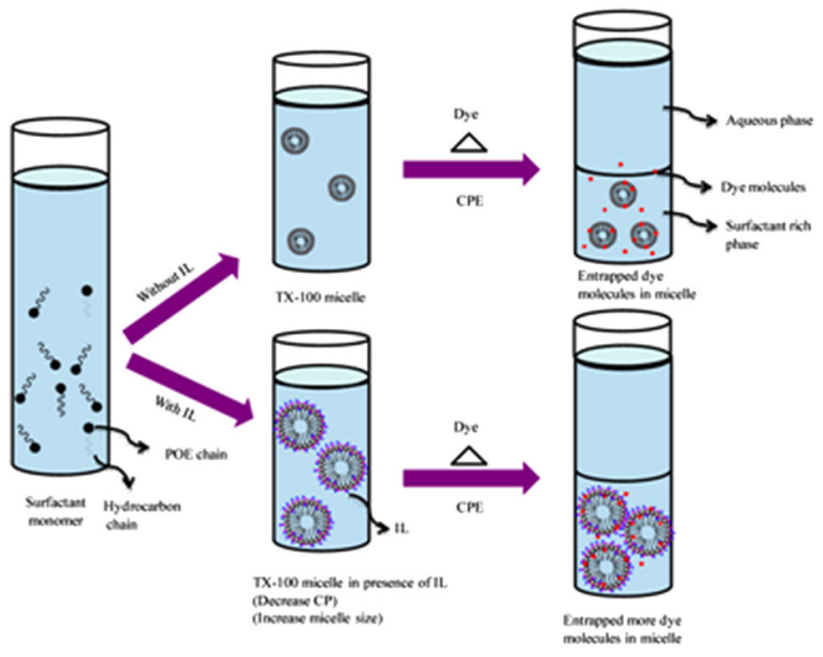

Keywords Langmuir isotherm · Nonionic surfactant . Thermodynamic parameter

\section{Introduction}

Dye containing waste stream is one of the major toxic industrial wastes. Various types of dyes are used in the process industries such as textile, paints, pulp and paper. The dyes present in wastewater will cause major 
environmental problems. Therefore, these colored waste need to be treated before disposal (Purkait et al. 2006). Among the various types of dye, Coralene red dye is a dispersed dye used in surrounding textile industries of Surat, India. It has been used in number of applications such as dyeing color for textiles and leather. The treatment of wastewater containing disperse dyes is a challenge because of their low water solubility and high capacity to form suspensions that inhibit most advanced oxidation processes. Further, CR dye contains anthraquinone-based aromatic structure which is highly stabilized by resonance and makes it very resistant to degradation (Yagub et al. 2014)

Many researchers have studied different techniques for the removal of colored dye from wastewater, including polyelectrolyte or micelle-enhanced ultrafiltration (Ouni and Dhahbi 2010; Pathak and Parikh 2011), various advanced oxidation processes (Nadupalli et al. 2011; Maheria and Chudasama 2007), nanofiltration (Zahrim et al. 2011) and waste material adsorption (Feng et al. 2011). Each method has its certain advantages and drawbacks. For example, in membrane separation processes, care is needed to avoid membrane fouling. Due to low biodegradability of dyes, conventional biological wastewater treatment cannot efficiently decolorize these dyes (Mondal et al. 2010). Thus, physical and chemical methods are adopted for dye wastewater treatment (Ngah et al. 2011). Adsorption is a common dye wastewater treatment method, but is usually costly and sometimes produces large amounts of waste sludge (Demirbas 2009). In the last decade, increasing interest on the use of aqueous micellar solution has been found in the field of separation science. An aqueous solution of a nonionic surfactant separates into two phases above the cloud point temperature, namely a surfactant-rich phase (coacervate phase), which has small volume as compared to the solution, and the other is dilute bulk aqueous phase containing surfactant concentration slightly above the critical micelle concentration $(\mathrm{cmc})$. The dye molecules present in aqueous solution of nonionic surfactant are distributed between the two phases above the cloud point temperature (Rosen 1978). This phenomenon is known as cloud point extraction (CPE). CPE is a potentially better alternative treatment method. Advantages of CPE are use of relatively nontoxic surfactants instead of toxic organic solvent, higher extraction efficiency, modest energy consumption, lower cost, experimental convenience, etc. In recent time, the use of CPE for treating environmental wastewater has rapidly progressed. Some examples of dyes that have been separated through this method are toxic Congo red, eosin (Purkait et al. 2005), nitrobenzene (Goswami et al. 2011), rhodamine B (Pourreza et al. 2008) and chrysoidine (Purkait et al. 2006).
Recently, application of inorganic salts in enhancement of the CPE efficiency of nonionic surfactants has been reported in number of studies (Purkait et al. 2005, 2006; Goswami et al. 2011). However, the literature review revealed that very few reports are available for the use of ILs as an additive with nonionic surfactants in CPE for metal separation (Gao et al. 2013; Bozkurt et al. 2012), but no report is available for dye removal. The unique physical and chemical properties of ILs make them most suitable candidates as an additive with nonionic surfactants in CPE. ILs have large number of applications in the area of organic synthesis (Cole-Hamilton 2003), catalysis (Parvulescu and Hardacre 2007), electrochemistry (Hapiot and Lagrost 2008) and chemical separation (Bates et al. 2002). Furthermore, ILs are considered as "green solvents" due to their nonvolatile nature with an added advantage of tuning their physical and chemical properties by suitable selection of cation, anion and substituent.

The main objective of the present study is to explore the novel application of IL as an additive with nonionic surfactant for CPE of toxic CR dye. The effect of various operating parameters such as temperature, time, concentrations of surfactant, dye and IL on the CPE of dye has been studied in order to establish optimum conditions. Detailed study on dye solubilization and various thermodynamic parameters has been carried out. Further, the design parameters at various temperatures were also developed to find out the dosage of surfactant concentration required for different feed concentrations of the $\mathrm{CR}$ dye. The probable mechanism to understand CPE with the combination of IL is also reported. Present study is carried out at SVNIT, Surat, Gujarat, India, during the year of 2013-2014.

\section{Materials and methods}

All reagents used were of analytical grade and used without further purification. The CR dye used in the present study (FW: 331, $\lambda_{\max }: 522 \mathrm{~nm}$ ) was received from Colourtex Ltd. (India). Triton X-100 (iso-octyl phenoxy polyethoxy ethanol, MW: $628, \lambda_{\max }: 226 \mathrm{~nm}$ ) was supplied by SigmaAldrich, India. The critical micellar concentration $(\mathrm{cmc})$ of TX-100 is $2.8 \times 10^{-4} \mathrm{M}$ (Rosen 1978). The cloud point (CP) of TX-100 in aqueous solution is $65{ }^{\circ} \mathrm{C}$ (Bhatt et al. 2013). The high-purity grade $\left[\mathrm{TEA}\left(\mathrm{BF}_{4}\right)\right] \mathrm{IL}$ was received with compliments from Tatva Chintan Pharma Chem Pvt. Ltd. (India). The aqueous solutions of all samples have been prepared using deionized water (Millipore Elix 3, USA) with surface tension $72 \pm 0.2 \mathrm{mNm}^{-1}$ and specific conductivity order $10^{-3} \mathrm{mScm}^{-1}$. The structure of [TEA $\left.\left(\mathrm{BF}_{4}\right)\right]$ IL, Triton X-100 surfactant and Coralene red dye are shown in Fig. 1. 
In the CPE experiments, various aqueous solutions of TX-100, [TEA $\left.\left(\mathrm{BF}_{4}\right)\right]$ IL and CR dye having different concentrations have been prepared by dissolving accurately weighed amount of surfactant, IL and dye, respectively. The concentration of dye in feed was varied as $1.51 \times 10^{-4}, \quad 3.02 \times 10^{-4}, 4.53 \times 10^{-4}$ and $6.04 \times$ $10^{-4} \mathrm{M}$. The concentration of TX-100 in feed has been varied as $0.05,0.1,0.15,0.2$ and $0.25 \mathrm{M}$. The effect of amount of IL on CPE of dye was studied using various concentration of IL as $0.01,0.04,0.07,0.1,0.5$ and $0.9 \mathrm{wt} \%$. Each experiment has been performed in a graduated test tube placed in a constant temperature bath $\left( \pm 0.1{ }^{\circ} \mathrm{C}\right)$ for the different span of times $(30,45,60$ and $75 \mathrm{~min}$ ) and at four different temperatures (343.15, 348.15, 353.15 and $358.15 \mathrm{~K})$. After complete phase separation, graduated test tube was removed from the temperature bath and cooled to room temperature. Samples were collected from the top of graduated test tube (dilute phase) using a micropipette, and the concentrations of both dye and surfactant have been determined by a spectrophotometer (VARIAN CARY 50). In order to study the thermodynamics and design parameters, the volumes of both phases (aqueous and coacervate) were measured. The calibration curves of CR and pure TX-100 solution have been developed for different concentrations at maximum absorption wavelengths 522 and $226 \mathrm{~nm}$, respectively, using standard method (Vogel 1970).

Dynamic light scattering (DLS) method was used to find out size of micelles formed in the TX-100 and TX-100-IL systems. DLS measurements were carried out with a Malvern Zetasizer Nano (Malvern, UK) as a function of temperature. The temperature of the sample was controlled within $\pm 0.1{ }^{\circ} \mathrm{C}$ by a Peltier-type electronic temperature controlling system attached to the apparatus. The measurements were performed twice for each sample, and a
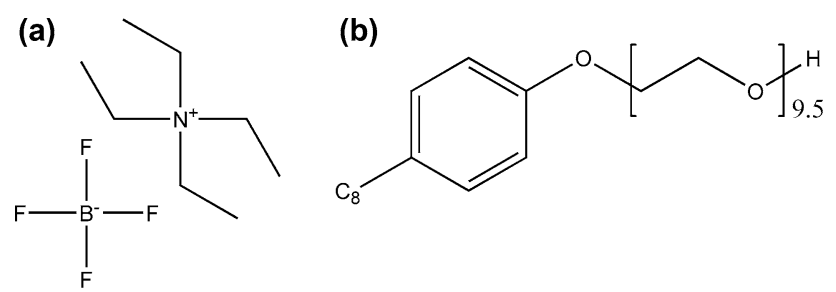

(c)

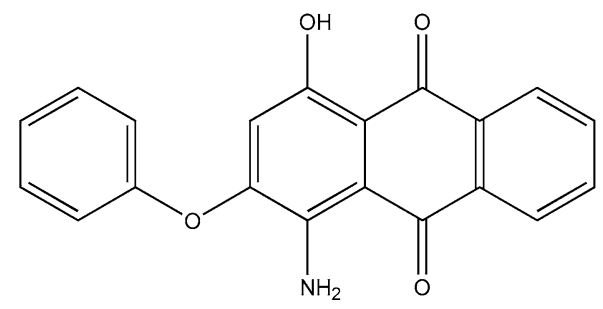

Fig. 1 Structure of $\left[\mathrm{TEA}\left(\mathrm{BF}_{4}\right)\right]$ IL (a), Triton X-100 surfactant (b) and Coralene red dye (c) good reproducibility was attained for particle size distribution.

To check the reliability of design parameters, analysis of real samples was carried out in different water samples (deionized water and river water). The deionized water was collected from research laboratory (Millipore Elix 3, USA) of SVNIT, Surat. River water was taken from the Tapi River, Surat. The aqueous and shrimp samples of dye were prepared by using deionized water and polluted water of river, respectively. In order to obtain aqueous and shrimp samples of dye, the different concentrations $\left(1.51 \times 10^{-4}\right.$ to $6.04 \times 10^{-4} \mathrm{M}$ ) of dye were spiked to deionized and river water. Afterward, aforementioned procedure was followed for CPE. The thermodynamics parameters were calculated using different equations mentioned in the Results and discussion section.

\section{Results and discussion}

This section is divided into three parts. In first part, the effect of different factors such as concentrations of TX100, dye and IL, time and temperature on the extraction extent of CR dye was discussed. The extraction mechanism is also reported in this part. The nature of solubilization isotherm at different temperatures has been presented in the second part. Thermodynamic parameters for CPE at different temperatures were explained in part three.

For CPE, the efficiency of extraction is defined below:

Efficiency of extraction $(E)=\left(1-\frac{C_{\mathrm{d}}}{C_{0}}\right) \times 100$

where $C_{0}$ and $C_{\mathrm{d}}$ are the initial and dilute phase concentrations of $\mathrm{CR}$, respectively.

\section{Factors influencing the extent of extraction}

\section{Effect of surfactant concentration on extraction}

Figure 2a depicts the effect of TX-100 concentration on the extraction efficiency of CR. It has been observed from the figure that the extraction of dye increases sharply with TX100 concentration up to $0.1 \mathrm{M}$, and beyond that it becomes gradual for both the cases (i.e., presence and absence of IL). The extraction efficiency found in absence of IL is about $87 \%$, and it increases significantly up to $99 \%$ with the addition of small amount of $(0.1 \mathrm{wt} \%)$ IL. The concentration of the micelles increases with surfactant concentration which ensuing in more dye solubilization in the micelles. Hence, the extraction efficiency of dye increases with surfactant concentration. The optimum surfactant concentration of $0.1 \mathrm{M}$ of $\mathrm{TX}-100$ has been selected in 

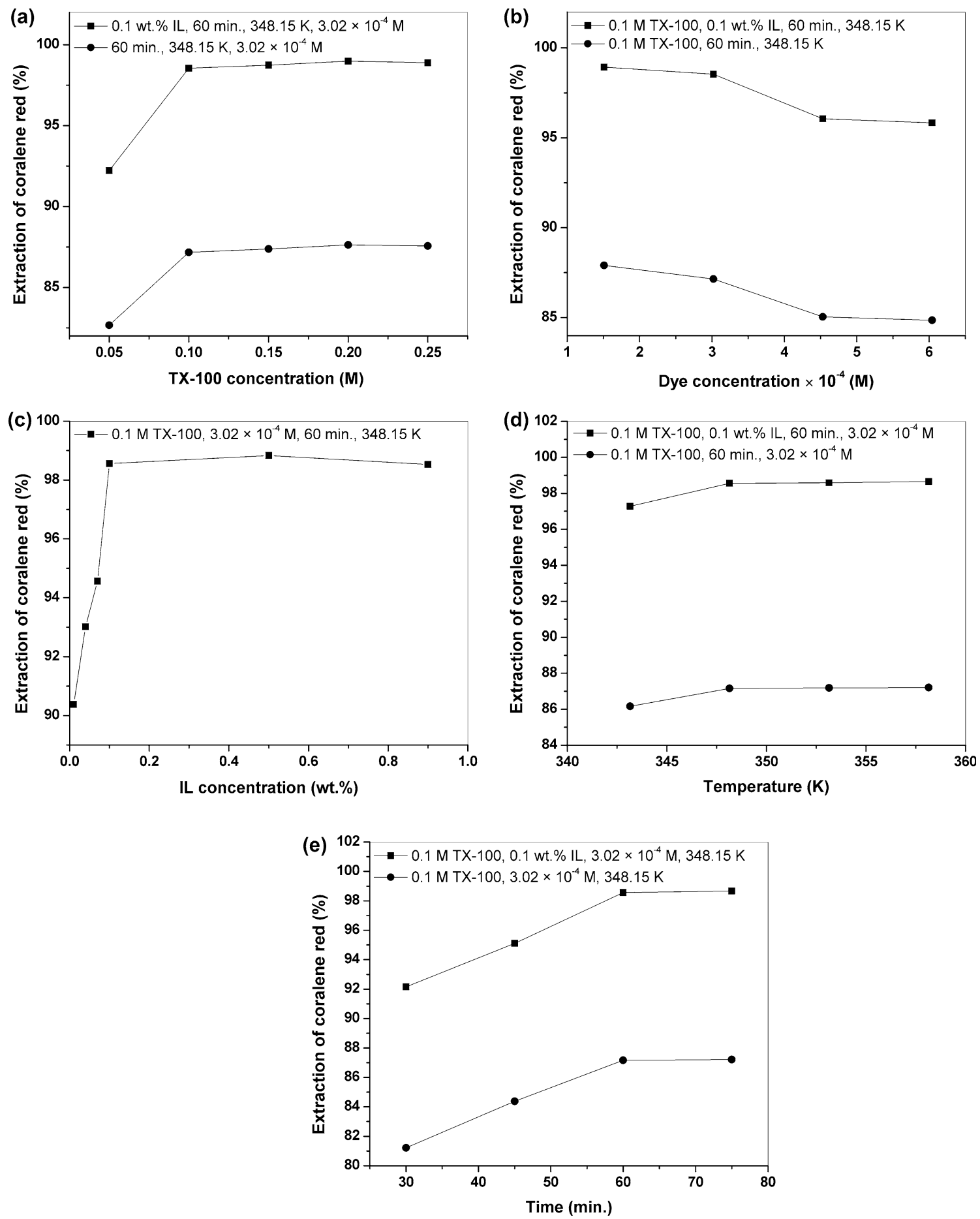

Fig. 2 Effect of TX-100 concentration (a), dye concentration (b), IL concentration (c), temperature (d) and time (e) on the extraction efficiency of dye

order to achieve maximum extraction efficiency for further study.

\section{Effect of dye concentration on extraction}

Figure $2 b$ depicts the effect of dye concentration on the extraction efficiency of CR. It evidently points out that the extraction of $\mathrm{CR}$ decreases with increment in dye concentration for both the cases. It is well known that the compounds (formamide, urea, etc.) that have water structure-breaking characteristics can increase the $\mathrm{cmc}$ of nonionic surfactant (Rosen 1978). A presence of structure-breaking ions can hinder the self-aggregation of water molecules. This will augment the extent of 
hydrogen bond formation between water molecules and ether groups in nonionic surfactants. In the present endeavor, the $\mathrm{CR}$ dye has alike active functional group. Thus, it may be presumed that $\mathrm{cmc}$ of the nonionic surfactant increases in presence of dye. It also entails that the number concentration of the micelles decreases with dye concentration. Therefore, decline in extraction efficiency with increment of feed dye concentration is due to increment of unsolubilized dye molecules in the dilute phase.

\section{Effect of IL concentration on extraction}

Figure $2 c$ depicts the effect of IL concentration on the extraction efficiency of CR. The results disclose that the extraction of CR increases significantly up to $0.1 \mathrm{wt} \%$, and thereafter it becomes nearly constant. Considering this, all the further experiments for design and thermodynamic parameters were performed with $0.1 \mathrm{wt} \% \mathrm{IL}$. A previous studies showed that $\left[\mathrm{TEA}\left(\mathrm{BF}_{4}\right)\right] \mathrm{IL}$ act as a salting-out agent and diminish the $\mathrm{CP}$ of the surfactant and that it endorses the dehydration of the ethoxy groups on the outer surface of the micelles (Bhatt et al. 2013). Furthermore, addition of IL increases the phase separation, micellar size and specific viscosity. This results in enhanced micelle concentration in the surfactant phase, escorting to solubilization of more dye (Bhatt et al. 2014).

\section{Effect of temperature on extraction}

Figure $2 \mathrm{~d}$ depicts the effect of temperature on the extraction efficiency of CR. It was observed from the figure that the maximum extraction efficiency was achieved at $348.15 \mathrm{~K}$. Therefore, the temperature of $348.15 \mathrm{~K}$ was adopted for the next experiment. The result reveals that the extraction of $\mathrm{CR}$ increases with temperature for both the cases due to fact that $\mathrm{cmc}$ of nonionic surfactants decreases at higher temperature. At higher temperatures, nonionic surfactants emerge relatively more hydrophobic, owing to an equilibrium shift that favors dehydration of the ether oxygen (Clint 1992). This leads to an increase in the number concentration of micelles. Hence, the solubilization capacity of the micellar solution increases with temperature, leading to an increase in the dye extraction.

\section{Effect of time on extraction}

Figure $2 \mathrm{e}$ depicts the effect of time on the extraction efficiency of CR. It is clear from the figure that the extraction of CR increases with time for both the cases and remained steady beyond $60 \mathrm{~min}$. Hence, $60 \mathrm{~min}$ time was selected for subsequent work.

\section{Extraction mechanism}

The clouding mechanism of surfactant with IL was already elucidated in previous work (Bhatt et al. 2013). As per this report, ILs such as $\operatorname{TEA}\left(\mathrm{BF}_{4}\right)$ demonstrate a multiple hydrogen bonding interaction with surfactant. Owing to these hydrogen bond interactions, the solvation around the polyoxyethyelene (POE) chain of the surfactant will take place, which must be the beginning of the solvophilicity of the POE chain in the TEA $\left(\mathrm{BF}_{4}\right)$ solution. In general, the strength of a hydrogen bond interaction shrinks with the increase in temperature. Thus, desolvation of the POE chain would occur at an elevated temperature, which leads to reduced solubility of the surfactant molecules and hence induces a phase separation. Thus, it can be assumed that IL plays a role as a salting-out agent, reduces the $\mathrm{CP}$ of the system and endorses the dehydration of the ethoxy groups on the outer surface of the micelles (Bhatt et al. 2013). Hence, addition of IL increases phase separation enhancing the micelle concentration in the coacervate phase, leading to solubilization of more dye. Furthermore, the values of mean hydrodynamic diameter $<\mathrm{D}>$ of micelles (see Fig. 3) obtained for $0.1 \mathrm{M}$ TX-100 and $0.1 \mathrm{M}$ TX-100 with $0.1 \mathrm{wt} \%$ IL increased gradually with an increase in temperature. Therefore, similar to the cases of an aqueous solution of surfactants, a steep growth of micelles takes place for TX-100 surfactant in water with $\mathrm{TEA}\left(\mathrm{BF}_{4}\right) \mathrm{IL}$ when temperature approaches the $\mathrm{CP}$. This micellar growth may be featured to the reduced solvophilicity of the POE chain at elevated temperatures (Inoue and Misono 2009; Bhatt et al. 2014). Actually, the desolvation of the POE chain associated with temperature rise is observed. The reduced solvophilicity of the POE chain would result in better attractive inter-micellar interaction, which leads to a

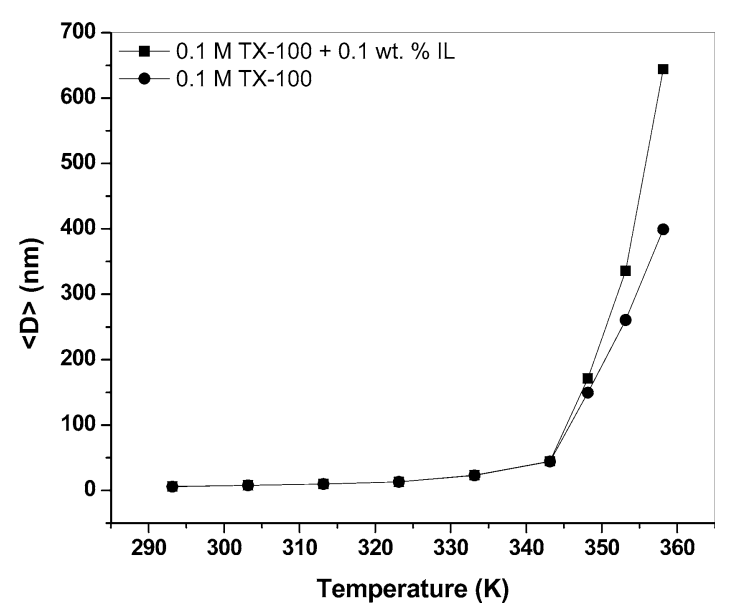

Fig. 3 Plot of mean hydrodynamic diameter, $<D>$, obtained for $0.1 \mathrm{M}$ TX-100 and $0.1 \mathrm{M}$ TX-100 $+0.1 \mathrm{wt} \% \mathrm{IL}$ as a function of temperature 
fusion of small micelles to form bigger ones. Figure 3 also clearly represents that the growth in micellar size is more in case of TX-100-IL mixture than pure TX-100 aqueous solution. The experimental data confirm more dye extraction efficiency in TX-100-IL mixture solution than TX-100 surfactant solution. This may be owing to formation of big micelles, which entrapped more dye molecules compared with pure TX-100 solution (refer Fig. 4).

\section{Solubilization isotherm}

Distribution of various concentrations of CR between the micellar-rich phase and aqueous phase at equilibrium can be explained by adsorption of the solute into the interior or outer palisade layers of micelles. Hence, assuming a homogeneous monolayer adsorption, the linearized Langmuir adsorption model can be applied using the following equation (Somorjai 1994; Chen et al. 2009):

$\frac{1}{q_{\mathrm{e}}}=\frac{1}{m}+\frac{1}{m n C_{\mathrm{e}}}$

where $q_{\mathrm{e}}$ is the mole of dye solubilized per mole of surfactant. $C_{\mathrm{e}}$ is the dilute phase equilibrium concentration of the dye. The constants $\mathrm{m}$ and $\mathrm{n}$ are the Langmuir constants, $\mathrm{m}$ implies the adsorption capacity, and $\mathrm{n}$ is related to the energy of adsorption. According to Eq. (2), a plot of $1 / q_{\mathrm{e}}$ versus $1 / C_{\mathrm{e}}$ (representative Fig. s1 given for CR dye concentration of $3.02 \times 10^{-4} \mathrm{M}$ ) gives a straight line with slope $1 / m n$ and intercept $1 / m$. The data of $m$ and $n$ are determined by using slope and intercept of the linear form (Eq. 2) of the Langmuir model. In order to precisely calculate the values of $m$ and $n$, three replications were carried out for each of the TX-100-CR systems. The values of slope and intercept are calculated and tabulated in Tables s1 and s2. The values of $m$ and $n$ of each TX-100CR system are calculated by the mean values of these slopes and intercepts, which are tabulated in Table s3.

As per the previous report of Chen et al. (Chen et al. 2009), the feed surfactant concentration required for the desired $\mathrm{CR}$ extraction was calculated by following equation,

$\operatorname{Cos}=\frac{E \operatorname{Co}}{m}+\frac{E}{m n(1-E)}$

where $\operatorname{Cos}$ is concentration of surfactant required with $0.1 \mathrm{wt} \%$ IL for desired level of extraction efficiency and $\mathrm{Co}$ is molar dye concentration in the feed. The values of $m$ and $n$ were computed for afore mentioned TX-100-CR

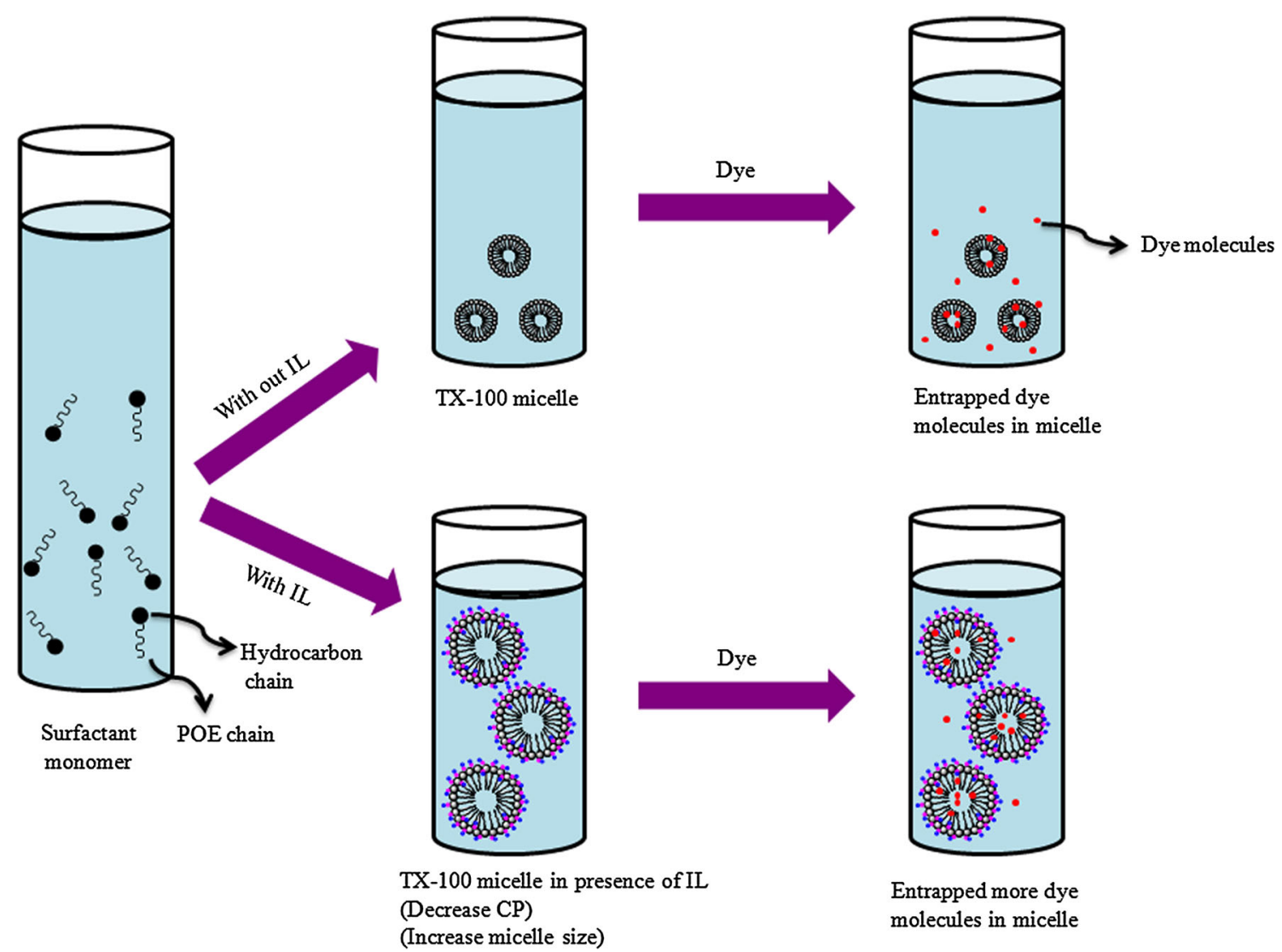

Fig. 4 Schematic representation of extraction mechanism 


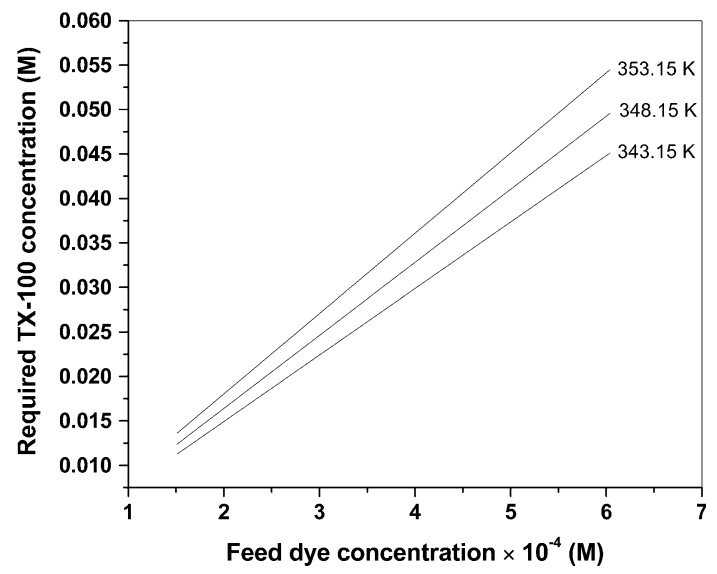

Fig. 5 Variation of required TX-100 concentration with 0.1 wt $\%$ IL for different feed dye concentrations at different temperatures with the desired extraction efficiency of $90 \%$

system. Therefore, using the concentration of CR in feed and a desired level of extraction efficiency $(E)$, Eq. (3) can be solved to obtain TX-100 concentration required with $0.1 \mathrm{wt} \% \mathrm{IL}$ (Cos). Figure 5 shows variation of required TX-100 concentrations for different feed CR concentrations (theoretical extraction) at different temperatures in the CPE processes when the desired extraction efficiency of $90 \%$. It is observed that the required surfactant concentration increases with the feed dye concentration and temperature.

\section{Analysis of real samples}

In order to test the reliability of the intended correlations between required surfactant concentration and the feed $\mathrm{CR}$ concentration, $\mathrm{CR}$ concentrations in the range $1.51 \times 10^{-4}$ to $6.04 \times 10^{-4} \mathrm{M}$ were spiked to aqueous samples and shrimp samples, respectively. Using Eq. (3), the TX-100 concentrations were calculated and used in the CPE processes. The results presented in Table 1 shows that good extraction efficiencies were attained for the removal of CR spiked to aqueous and shrimp samples. However, a spiked sample shows relatively less extraction efficiency than aqueous samples, which may be due to the interference of other impurities present in the spiked shrimp samples.

\section{Thermodynamic parameters}

The thermodynamic parameters Gibbs free energy $\left(\Delta G^{0}\right)$, enthalpy of solubilization $\left(\Delta H^{0}\right)$ and entropy of solubilization $\left(\Delta S^{0}\right)$ for extraction process are determined by using the following equations (Purkait et al. 2009),

$\Delta G^{0}=\Delta H^{0}-T \Delta S^{0}$
Table 1 Extraction of dye in water and shrimp samples

\begin{tabular}{llll}
\hline $\begin{array}{l}\text { Coralene red } \\
\text { added } \\
(\mathrm{M}) \times 10^{4}\end{array}$ & $\begin{array}{l}\text { TX-100 } \\
\text { added }^{\mathrm{a}}(\mathrm{M}) \times 10^{2}\end{array}$ & $\begin{array}{l}\text { Extraction from } \\
\text { water samples } \\
(\%)\end{array}$ & $\begin{array}{l}\text { Extraction from } \\
\text { shrimp samples } \\
(\%)\end{array}$ \\
\hline 1.51 & 1.36 & 90.04 & 86.41 \\
2.26 & 2.04 & 90.49 & 86.96 \\
3.02 & 2.72 & 90.87 & 87.51 \\
4.53 & 4.09 & 91.39 & 88.85 \\
5.28 & 4.77 & 91.69 & 89.08 \\
6.04 & 5.45 & 91.85 & 89.53 \\
\hline
\end{tabular}

a Added by the calculated concentration

$\log \left(q_{\mathrm{e}} / C_{\mathrm{e}}\right)=\frac{\Delta S^{0}}{2.303 R}+\frac{-\Delta H^{0}}{2.303 \mathrm{RT}}$

where $q_{\mathrm{e}}$ is the mole of dye solubilized per mole of nonionic surfactant. $C_{\mathrm{e}}$ is equilibrium concentration of dye (moles/L) before the completion of two phases and $T$ is the temperature in Kelvin. $q_{\mathrm{e}} / C_{\mathrm{e}}$ is called the solubilization affinity. The values of $\Delta G^{0}$ have been calculated by knowing the $\Delta H^{0}$ and $\Delta S^{0} . \Delta H^{0}$ and $\Delta S^{0}$ values are obtained from a plot of $\log \left(q_{\mathrm{e}} / C_{\mathrm{e}}\right)$ versus $1 / T$, from Eq. (5). Once these two parameters are obtained, $\Delta G^{0}$ is determined from Eq. (4). The values of $\Delta G^{0}, \Delta H^{0}$ and $\Delta S^{0}$ are calculated at different experimental conditions and reported methodically.

\section{Determination of change in Gibbs free energy $\left(\Delta G^{0}\right)$ during CPE process}

Variations of $\Delta G^{0}$ with temperature at four different surfactant concentrations and at constant dye concentration $\left(3.02 \times 10^{-4} \mathrm{M}\right)$ for TX-100 (including fixed $0.1 \mathrm{wt} \% \mathrm{IL}$ ) are shown in Fig. 6a. It can been observed from the figure and Table 2 that the value of $\Delta G^{0}$ raises linearly with temperature. The negative values of $\Delta G^{0}$ imply that the dye solubilization process is spontaneous and thermodynamically favorable. The observed increase in negative values of $\Delta G^{0}$ on elevating temperature revealed great driving force for solubilization as indicated from the great extent of $\mathrm{CR}$ extraction on increasing temperature. The decrease in $-\Delta G^{0}$ values with the increase in surfactant concentration owes to decrease in amount of dye solubilization.

Figure s2 demonstrates the change of $\Delta G^{0}$ with initial $\mathrm{CR}$ concentration. Figure reveals that at constant surfactant concentration and temperature, the values of $\Delta G^{0}$ decreases with the $\mathrm{CR}$ concentration. The $\mathrm{cmc}$ values of surfactant decreases with increment of $\mathrm{CR}$ concentration ensuing in greater surfactant concentration in the micellar phase. As a result, the amount of CR solubilization per mole of surfactant decreases. This is validated by the lower extraction efficiency at higher CR concentration. 
(a)

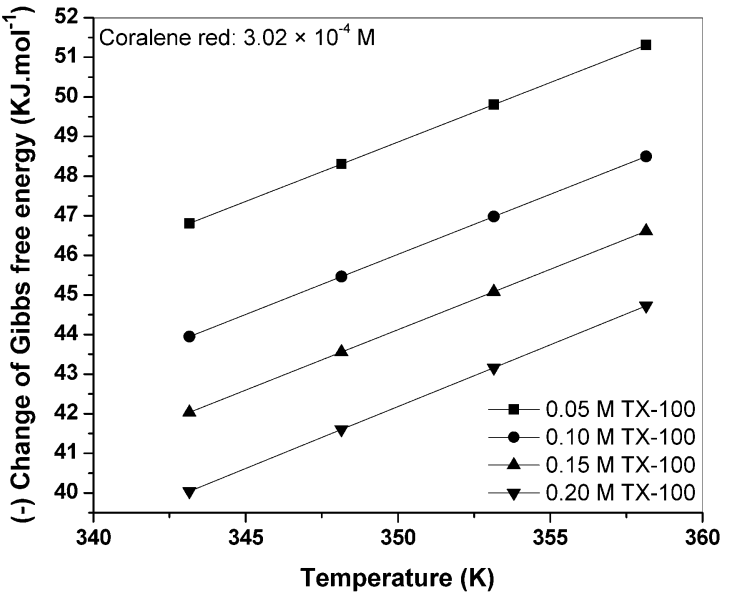

(b)

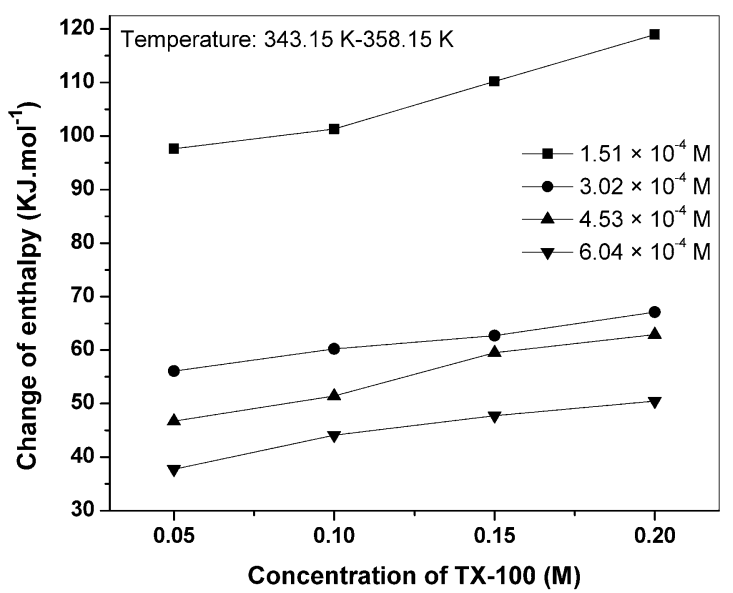

(c)

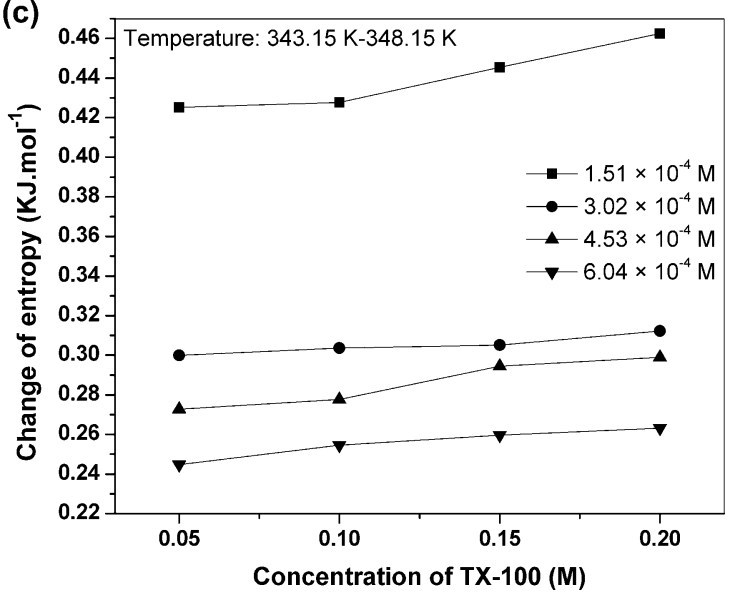

Fig. 6 Variation in Gibbs free energy change $\left(\Delta G^{0}\right)$ with temperature at different TX-100 +0.1 wt $\%$ IL concentrations (a), enthalpy change $\left(\Delta H^{0}\right)(\mathbf{b})$ and entropy change $\left(\Delta S^{0}\right)(\mathbf{c})$ with different TX-100 +0.1 wt $\%$ IL concentrations for CPE of dye

\section{Determination of change in enthalpy $\left(\Delta H^{0}\right)$ during CPE process}

Figure $6 \mathrm{~b}$ represents the variation of enthalpy change $\left(\Delta H^{0}\right)$ during $\mathrm{CPE}$ of $\mathrm{CR}$ dye at different operating conditions. It has been observed from Fig. $6 \mathrm{~b}$ that the value of $\Delta H^{0}$ increases with TX-100 concentrations but declines with $\mathrm{CR}$ concentrations. The increase in $\Delta H^{0}$ value with initial surfactant concentration is owing to the increase in solubilization capacity. The positive values of $\Delta H^{0}$ reflects the endothermic nature of solubilization affinity of $\mathrm{CR}$ in the micellar-rich phase (coacervate phase). Thus, the number of hydrophobic micelles in the micellar-rich phase becomes more, while the $\mathrm{cmc}$ of nonionic surfactant decreases by increasing temperature, causing an increase in the extraction percentage of dye (El-Shahawi et al. 2013). Figure s3 shows that the decrease in $\Delta H^{0}$ value with increment of $\mathrm{CR}$ concentration at a fixed surfactant concentration is due to the decrease in the amount of $\mathrm{CR}$ solubilization per mole of surfactant as discussed in the previous section.

\section{Determination of change in entropy $\left(\Delta S^{0}\right)$ during CPE process}

The variation of entropy change $\left(\Delta S^{0}\right)$ during CPE of CR dye at different operating conditions is presented in Figs. $6 \mathrm{c}$ and $\mathrm{s} 4$. For all the cases, $\Delta S^{0}$ are positive and that imitates good affinity and organization of the dye molecules in a more random fashion in micellar-rich phase and it is in good agreement with the data reported for azo dyes solubilization in Triton X-100 and Triton X-114 (Purkait et al. 2009; Zhou et al. 2009). Entropy depends on free surfactant molecules and unsolubilized dye molecule in the CPE system. It depends mostly on the surfactant molecules, as the concentration of surfactant is much higher than dye in the solution. For all cases, entropy values decreases with dye concentration and increases with 
Table 2 Change in Gibbs free energy $\left(\Delta G^{0}\right)$ for the CPE of CR using TX-100 with $0.1 \mathrm{wt} \%$ IL at different temperatures and concentrations of dye and TX100

\begin{tabular}{|c|c|c|c|c|c|}
\hline \multirow[t]{2}{*}{ TX-100 (M) } & \multirow[t]{2}{*}{ Coralene red $\times 10^{4}(\mathrm{M})$} & \multicolumn{4}{|c|}{$-\Delta G^{0}(\mathrm{KJ} / \mathrm{mol})$ at temperature $(\mathrm{K})$} \\
\hline & & 343.15 & 348.15 & 353.15 & 358.15 \\
\hline 0.05 & 1.51 & 48.28 & 50.41 & 52.53 & 54.66 \\
\hline 0.10 & 1.51 & 45.45 & 47.59 & 49.72 & 51.86 \\
\hline 0.15 & 1.51 & 42.63 & 44.86 & 47.08 & 49.31 \\
\hline 0.20 & 1.51 & 39.76 & 42.07 & 44.38 & 46.70 \\
\hline 0.05 & 4.53 & 46.86 & 48.23 & 49.59 & 50.95 \\
\hline 0.10 & 4.53 & 43.84 & 45.23 & 46.62 & 48.01 \\
\hline 0.15 & 4.53 & 41.52 & 42.99 & 44.46 & 45.94 \\
\hline 0.20 & 4.53 & 39.70 & 41.20 & 42.69 & 44.19 \\
\hline 0.05 & 6.04 & 46.25 & 47.47 & 48.70 & 49.92 \\
\hline 0.10 & 6.04 & 43.28 & 44.56 & 45.83 & 47.10 \\
\hline 0.15 & 6.04 & 41.33 & 42.63 & 43.93 & 45.22 \\
\hline 0.20 & 6.04 & 39.86 & 41.17 & 42.49 & 43.80 \\
\hline
\end{tabular}

surfactant concentration. As initial surfactant concentration increases, the number concentration of surfactant molecule increases in the dilute phase. Due to increment of free surfactant molecule in the dilute phase, $\Delta S^{0}$ value increases with initial surfactant concentration. At a fixed surfactant concentration, cmc of surfactant molecule decreases with increase in dye concentration. The decrease in $\Delta S^{0}$ value with increment of dye concentration is due to reduction in number of surfactant molecules in the dilute phase.

\section{Conclusion}

The adequate removal of toxic $\mathrm{CR}$ dye from wastewater was carried out using Triton $\mathrm{X}-100$ as a nonionic surfactant with $\left[\mathrm{TEA}\left(\mathrm{BF}_{4}\right)\right]$ IL by $\mathrm{CPE}$ method. The inclusion of small quantity of IL enhanced the extraction efficiency. The optimum IL concentration is found to be about $0.1 \mathrm{wt} \%$. A Langmuir-type isotherm is found to adequately describe the solubilization isotherms of dye in TX-100. The relationship between the feed concentration of $\mathrm{CR}$ and the TX-100 + 0.1 wt\% IL concentration required is linear, which may be useful to design a CPE procedure. The required surfactant concentration increased with increment of temperature and dye concentration. The detailed study of thermodynamic parameters demonstrated that changes in Gibbs free energy increased with temperature and decreased with both surfactant and dye concentration, whereas change in enthalpy and entropy increased with surfactant concentration and decreased with dye concentration. The nature of extraction was found spontaneous and endothermic. The positive values of $\Delta S^{0}$ dictate that solubilized CR dye molecules are organized in more random fashion in micellar-rich phase. The present study explores easy, rapid, safe and low-cost methodology for the separation of CR dye, which can be further useful for the removal of other hazardous pollutants from water bodies.

Acknowledgments The authors would like to acknowledge SVNIT, Surat, for providing research facilities.

\section{Compliance with ethical standards}

Conflict of interest The authors have declared no conflict of interest.

\section{References}

Bates ED, Mayton RD, Ntai I, Davis JH Jr (2002) $\mathrm{CO}_{2}$ capture by a task-specific ionic liquid. J Am Chem Soc 124:926-927

Bhatt D, Maheria KC, Parikh J (2013) Studies on surfactant-ionic liquid interaction on clouding behaviour and evaluation of thermodynamic parameters. J Surf Deterg 16:547-557

Bhatt D, Maheria KC, Parikh J (2014) Mixed system of ionic liquid and non-ionic surfactants in aqueous media: surface and thermodynamic properties. J Chem Thermodyn 74:184-192

Bozkurt SS, Ocakoglu K, Merdivan M (2012) Separation and preconcentration of mercury in water samples by ionic liquid supported cloud point extraction and fluorimetric determination. Microchim Acta 177:47-52

Chen J, Mao J, Mo X, Hang J, Yang M (2009) Study of adsorption behavior of malachite green on polyethylene glycol micelles in cloud point extraction procedure. Colloids Surf A 345:231-236

Clint JH (1992) Surfactant aggregation. Blackie, Glasgow

Cole-Hamilton DJ (2003) Homogeneous catalysis-new approaches to catalyst separation, recovery, and recycling. Science 299:1702-1706

Demirbas A (2009) Agricultural based activated carbons for the removal of dyes from aqueous solutions: a review. J Hazard Mater 167(1-3):1-9

El-Shahawi MS, Hamza A, Al-Sibaai AA, Bashammakh AS, Al-Saidi HM (2013) A new method for analysis of sunset yellow in food samples based on cloud point extraction prior to spectrophotometric determination. J Ind Eng Chem 19:529-535

Feng Y, Yang F, Wang Y, Ma L, Wu Y, Kerr PG, Yang L (2011) Basic dye adsorption onto an agro-based waste material- 
Sesame hull (Sesamum indicum L.). Bioresour Technol 102(22):10280-10285

Gao S, Sun T, Chen Q, Shen X (2013) Improvement of the cloud point extraction of uranyl ions by the addition of ionic liquids. J Hazard Mater 263:562-568

Goswami A, Nath J, Purkait MK (2011) Cloud point extraction of nitrobenzene using TX-100. Sep Sci Technol 46:744-753

Hapiot P, Lagrost C (2008) Electrochemical reactivity in roomtemperature ionic liquids. Chem Rev 108:2238-2264

Inoue T, Misono T (2009) Cloud point phenomena for POE-type nonionic surfactants in imidazolium-based ionic liquids: effect of anion species of ionic liquids on the cloud point. J Colloid Interface Sci 337:247-253

Maheria KC, Chudasama UV (2007) Sorptive removal of dyes using titanium phosphate. Ind Eng Chem Res 46:6852-6857

Mondal PK, Ahmad R, Usmani SQ (2010) Anaerobic biodegradation of triphenylmethane dyes in a hybrid UASFB reactor for wastewater remediation. Biodegradation 21(6): 1041-1047

Nadupalli S, Koorbanally N, Jonnalagadda SB (2011) Chlorine dioxide-facilitated oxidation of the azo dye amaranth. J Phys Chem A 115(42):11682-11688

Ngah WSW, Teong LC, Hanafiah MAKM (2011) Adsorption of dyes and heavy metal ions by chitosan composites: a review. Carbohydr Polym 83(4):1446-1456

Ouni H, Dhahbi M (2010) Removal of dyes from wastewater using polyelectrolyte enhanced ultrafiltration (PEUF). Desalin Water Treat 22(1-3):355-362

Parvulescu VI, Hardacre C (2007) Catalysis in ionic liquids. Chem Rev 107:2615-2665

Pathak N, Parikh J (2011) Textile wastewater treatment using a UF hollow-fibre submerged membrane bioreactor (SMBR). Environ Technol 32(11):1247-1257
Pourreza N, Rastegarzadeh S, Larki A (2008) Micelle-mediated cloud point extraction and spectrophotometric determination of rhodamine B using Triton X-100. Talanta 77(2):733-736

Purkait MK, Banerjee S, Mewara S, DasGupta S, De S (2005) Cloud point extraction of toxic eosin dye using Triton X-100 as nonionic surfactant. Water Res 39:3885-3890

Purkait MK, DasGupta S, De S (2006) Performance of TX-100 and TX-114 for the separation of chrysoidine dye using cloud point extraction. J Hazard Mater 137(2):827-835

Purkait MK, Gupta SD, De S (2009) Determination of thermodynamic parameters for the cloud point extraction of different dyes using TX-100 and TX-114. Desalination 244:130-138

Rosen MJ (1978) Surfactants and interfacial phenomena. Wiley, New York

Somorjai GA (1994) Introduction to surface chemistry and catalysis. Wiley, New York

Vogel AI (1970) Text book of practical organic chemistry. Longmans, London

Yagub MT, Sen KT, Afroze S, Ang HM (2014) Dye and its removal from aqueous solution by adsorption: a review. Adv Colloid Interface Sci 209:172-184

Zahrim AY, Tizaoui C, Hilal N (2011) Coagulation with polymers for nanofiltration pre-treatment of highly concentrated dyes: a review. Desalination 266(1-3):1-16

Zhou Z, Zhao D, Wang J, Zhao W, Yang M (2009) Study of cloud point extraction and high-performance liquid chromatographic determination of isoniazid based on the formation of isonicotinylhydrazone. J Chromatogr A 1216:30-35 